\section{BMJ Open} Ophthalmology

\title{
Quantification of the peripheral vitreous after vitreous shaving using intraoperative optical coherence tomography
}

\author{
Koichi Nishitsuka (1) , Katsuhiro Nishi, Hiroyuki Namba, Yutaka Kaneko, \\ Hidetoshi Yamashita
}

To cite: Nishitsuka K, Nishi K, Namba $\mathrm{H}$, et al. Quantification of the peripheral vitreous after vitreous shaving using intraoperative optical coherence tomography. BMJ Open Ophthalmology 2021;6:e000605. doi:10.1136/ bmjophth-2020-000605

Received 20 August 2020 Revised 9 February 2021 Accepted 11 February 2021
Check for updates

(C) Author(s) (or their employer(s)) 2021. Re-use permitted under CC BY-NC. No commercial re-use. See rights and permissions. Published by BMJ.

Department of Ophthalmology and Visual Sciences, Yamagata University Faculty of Medicine, Yamagata, Japan

Correspondence to Koichi Nishitsuka; mlc12186@ nifty.com

\section{ABSTRACT}

Objective To evaluate the technique of peripheral vitreous shaving during vitrectomy, we measured the residual peripheral vitreous using intraoperative optical coherence tomography (iOCT).

Methods and Analysis This retrospective study included 44 eyes that underwent 25-gauge pars plana vitrectomy with IOCT by a single surgeon. In all cases, the surgery was performed via ocular indentation. Cases in group A were treated with vitreous shaving under slit lamp microscope illumination, whereas cases in group B were treated with vitreous shaving under a wide-angle viewing system. Residual peripheral posterior vitreous-cortex detachment (PVD) was quantified by iOCT.

Results IOCT image analysis enabled the visualisation of the angle formed between the retina and peripheral PVD around the vitreous base in all cases. After the completion of vitreous shaving, the mean length of the peripheral PVD was shorter in group $A(961.7 \pm 214.7 \mu \mathrm{m})$ compared with group $B(1925.3 .7 \pm 626.1 \mu \mathrm{m} ; \mathrm{p}<0.01)$.

Conclusion iOCT enabled the quantification of the residual peripheral vitreous after vitreous shaving. The quantification of the residual peripheral vitreous after different shaving procedures will be important for advocating appropriate vitreous shaving in future.

\section{INTRODUCTION}

Pars plana vitrectomy (PPV) has been gaining popularity for the treatment of primary rhegmatogenous retinal detachment (RRD) since $2008 .^{12}$ The vitreous near the vitreous base was thought to be associated with the formation of retinal breaks, peripheral vitreous shaving was performed to eliminate the traction of the vitreous to the retina. ${ }^{3-5}$ Two approaches can be used for vitreous shaving, that is, the performance of an ocular indentation to observe the periphery of the retina using either a slit lamp microscope illumination or a wide-angle viewing system. Recently, Tabandeh et alreported the outcome of retinal detachment surgery without scleral depressed shaving of the vitreous base. ${ }^{6}$ However, little is known regarding the extent of vitreous

\section{Key messages}

Peripheral vitreous shaving was performed to eliminate the traction of the vitreous to the retina. However, little is known regarding the extent of vitreous shaving that is appropriate in this context because no method is available to quantify the residual vitreous objectively.

Intraoperative optical coherence tomography (iOCT) could detect the peripheral posterior vitreous detachment (PVD) and vitreous base.

- We quantified the residual peripheral vitreous after vitreous shaving using $\mathrm{IOCT}$ by measuring the length of the peripheral PVD.

Quantification of the residual peripheral vitreous after different shaving procedures will be important for advocating appropriate vitreous shaving.

shaving that is appropriate in this context because no method is available to quantify the residual vitreous objectively. Although the amount of resection of the vitreous body varies according to the surgical procedures and the surgeon's skill, it is necessary to determine the amount of vitreous ablation that is adequate in this context.

To observe the peripheral vitreous and retina objectively, we developed a procedure that uses intraoperative optical coherence tomography (iOCT). ${ }^{7}$ The use of iOCT may help detect the peripheral part of the vitreous, including the vitreous base and peripheral posterior vitreous detachment (PVD). ${ }^{7}$ For the development of a method of verification of the peripheral vitreous, in this study, we attempted to quantify the peripheral residual vitreous associated with vitreous shaving using iOCT.

\section{MATERIAL AND METHODS}

We performed a retrospective analysis of 44 eyes treated with PPV by a single surgeon. These cases were treated using different 
vitreous-shaving procedures. Cases treated between May and July 2015 underwent shaving under slit lamp microscope illumination (group A). Cases treated between May and December 2018 underwent shaving under a wide-angle viewing system (group B). All patients were treated by hospitalisation, and all the work was approved by the institutional review board of Yamagata University Faculty of Medicine (R1-314). The procedure conformed to the tenets of the Declaration of Helsinki. Patients or the public were not involved in the design, or conduct, or reporting or dissemination of our research.

\section{Surgical procedure of vitreous shaving}

All cases were treated using a 25G-PPV wide-angle noncontact viewing system (Resight; Carl Zeiss Meditec AG, Jena, Germany) for against cause disease with the Constellation Vision System (Alcon Laboratories, Fort Worth, Texas, USA) or an EVA vitrectomy system (DORC, Zuidland, The Netherlands). The peripheral vitreous and retina were detected using iOCT (RESCAN; Carl Zeiss Meditec AG, Jena, Germany), as described previously, ${ }^{7}$ and recorded for postoperative analysis. The procedures used for the peripheral detection of vitreous detachment via iOCT were as follows. Step 1: performance of a scleral indentation to observe the peripheral part of the retina using a slit lamp microscope illumination. Step 2: activation of iOCT and adjustment of OCT by focusing on the images of the peripheral retina and vitreous. In group A, vitreous shaving was carried out under a slit lamp microscope illumination (Visulux; Zeiss, Oberkochen, Germany) with ocular indentation. In group B, vitreous shaving was performed under a wide-angle noncontact viewing system using chandelier endoillumination (TotalView Chandelier; DORC, Zuidland, The Netherlands) with ocular indentation.

\section{Quantification of residual vitreous using IOCT}

Recorded iOCT findings were analysed by converting the still image from a movie (figure 1). The peripheral PVD, retina and vitreous base were visualised clearly and formed angles. ${ }^{7}$ In this study, we named this finding vitreoretinal angle. The amount of residual vitreous cortex was defined as the length of peripheral PVD measured from the vertex point of the vitreoretinal angle. The length of the peripheral PVD (figure 1, triangle) was

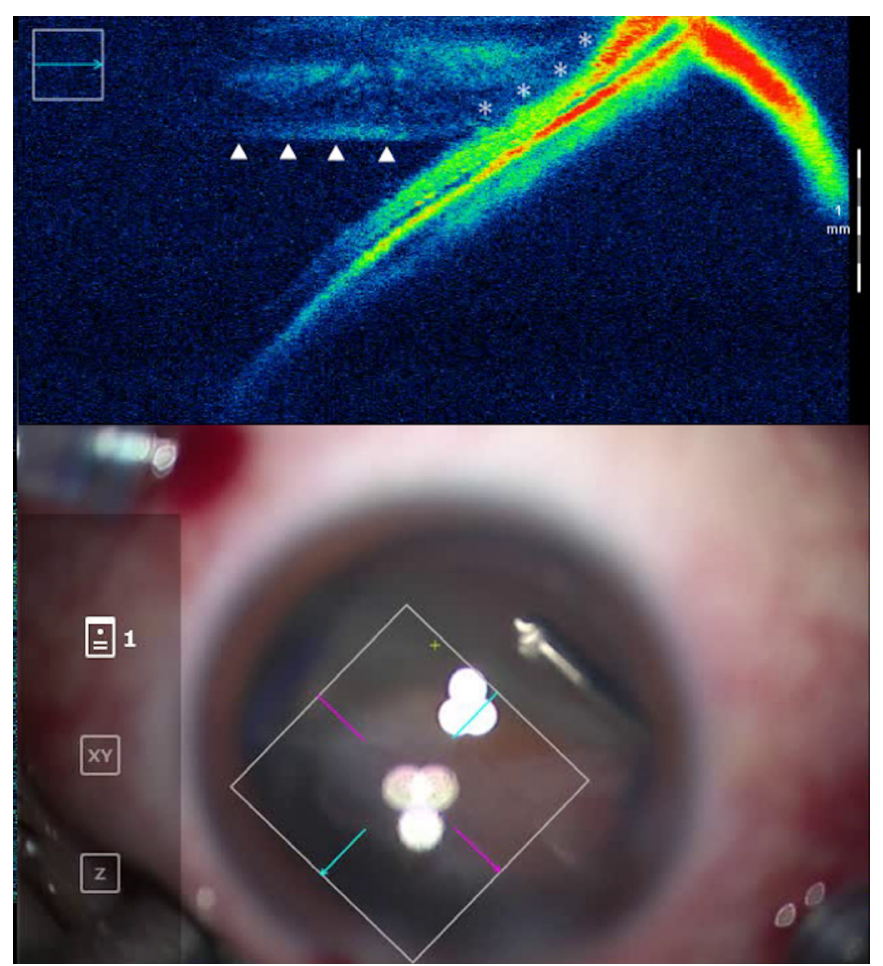

Figure 1 Findings of the peripheral vitreous and retina using intraoperative optical coherence tomography vitreoretinal angle formed between the retina and the peripheral posterior vitreous detachment (triangle), near the vitreous base (asterisk).

measured in pixel with ImageJ software and calculated by OCT scale bar or scan depth.

\section{Patient involvement}

Patients were not directly involved in the design of this study.

\section{Statistical analyses}

We used the $\chi^{2}$ test, Fisher's exact test, Wilcoxon signedrank test and Mann-Whitney U test for statistical analysis. Statistical significance was set at $\mathrm{p}<0.01$ for all analyses. Analyses were conducted using PASW Statistics 18 (SPSS, Chicago, Illinois, USA).

Table 1 Patient characteristics in this study

\begin{tabular}{|c|c|c|c|}
\hline Characteristics & Group A ( $n=24)$ & Group B $(n=20)$ & $P$ value \\
\hline Age (years), mean $\pm S D$ & $57.9 \pm 15.5$ & $61.5 \pm 10.5$ & 0.582 \\
\hline Sex, female/male & $54.2 \%$ & $25.0 \%$ & 0.213 \\
\hline Disease leading to the vitrectomy & & & 0.302 \\
\hline RRD & 14 & 16 & \\
\hline PDR & 8 & 3 & \\
\hline Others $^{*}$ & 2 & 1 & \\
\hline
\end{tabular}

*Others include macular hole (group A), epiretinal membrane (group A) and branched retinal vein occlusion (group B).

PDR, proliferative diabetic retinopathy; RRD, rhegmatogenous retinal detachment. 

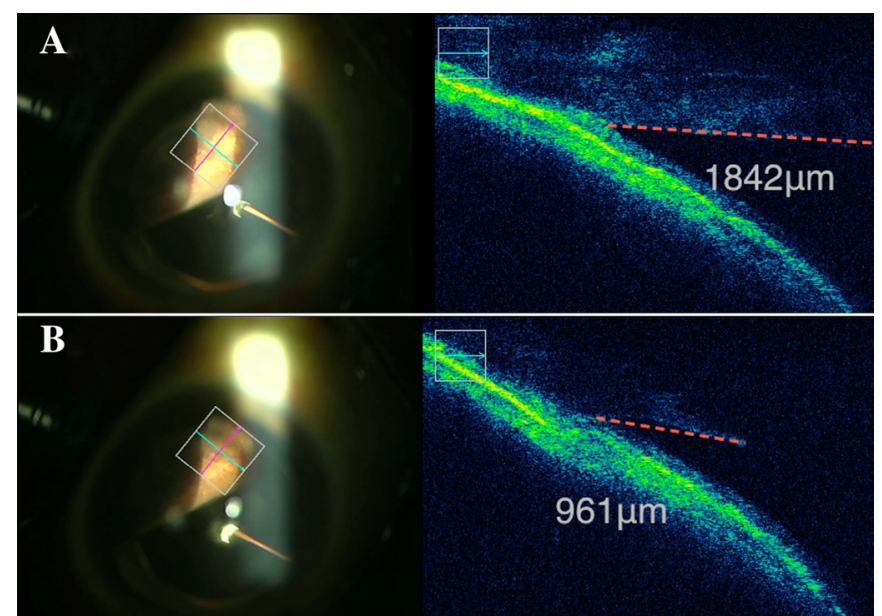

Figure 2 Intraoperative optical coherence tomography findings before and after finishing vitreous shaving in group A. A woman in her early 60 s with rhegmatogenous retinal detachment. Vitreous shaving was carried out under a slit lamp microscope illumination with ocular indentation. (A) Before finishing shaving, the length of the peripheral posterior vitreous detachment in the vitreo-retinal angle was $1842 \mu \mathrm{m}$. (B) After finishing shaving, the length of the peripheral posterior vitreous detachment in the vitreo-retinal angle was $961 \mu \mathrm{m}$.

\section{RESULTS}

A total of 44 eyes were included in the study, 24 eyes in group A and 20 eyes in group B. The patient characteristics are presented in table 1 . There were 11 women in group A and 5 women in group B (Fisher's exact test, $\mathrm{p}=0.213)$. The mean age $\pm \mathrm{SD}$ was $57.9 \pm 15.5$ years in group A and $61.5 \pm 10.5$ years in group B (Mann-Whitney $\mathrm{U}$ test, $\mathrm{p}=0.582$ ). The disease leading to the vitrectomy was RRD in 14 eyes, proliferative diabetic retinopathy (PDR) in eight eyes, macular hole in one eye and epiretinal membrane in one eye in group A; and RRD in 16 eyes, PDR in 3 eyes and branched retinal vein occlusion in 1 eye in group $B\left(\chi^{2}\right.$ test, $\left.p=0.213\right)$.

In all cases, the vitreoretinal angle formed by the retina and peripheral PVD near the vitreous base could be verified. Figure 2 shows the case of iOCT finding before and after finishing the vitreous shaving in group A. Table 2 shows the comparison of the quantified peripheral vitreous cortex using iOCT during vitreous shaving in group A. The length of the peripheral PVD in the vitreoretinal angle, as the residual vitreous, was shorter after finishing vitreous shaving $(961.7 \pm 214.7 \mu \mathrm{m})$ compared with that observed before finishing vitreous

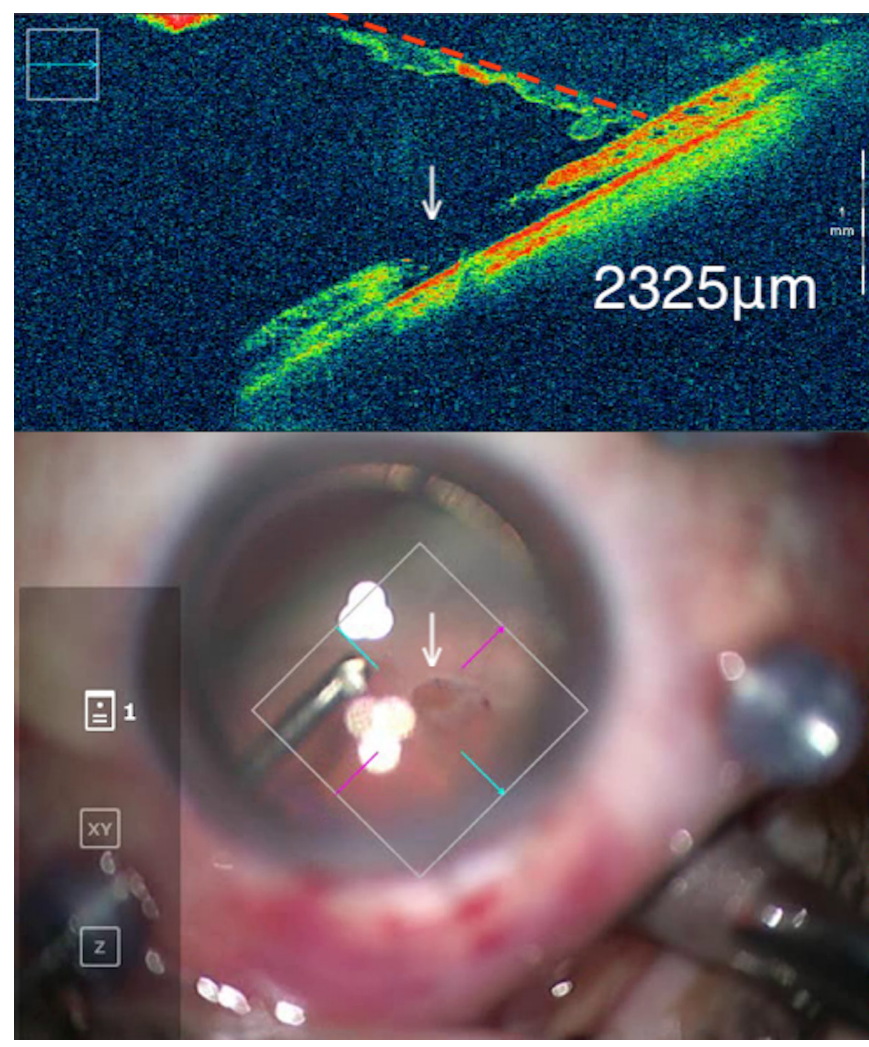

Figure 3 Intraoperative optical coherence tomography (iOCT) findings after finishing vitreous shaving in Group B. A man in his late 50 s with rhegmatogenous retinal detachment. Vitreous shaving was performed under a wide-angle noncontact viewing system using chandelier endoillumination with ocular indentation. IOCT finding shows the length of the peripheral posterior vitreous detachment in the vitreo-retinal angle $(2325 \mu \mathrm{m})$ and retinal tear (arrow).

shaving (2124.8 $\pm 292.8 \mu \mathrm{m})$ (Wilcoxon signed-rank test, $\mathrm{p}<0.01)$. Figure 3 shows the case of iOCT finding after finishing the vitreous shaving in group B. Table 3 shows the comparison of the residual vitreous cortex after finishing vitreous shaving between group A and group B. The length of the peripheral PVD in the vitreoretinal angle, as the residual vitreous, was shorter in group A $(961.7 \pm 214.7 \mu \mathrm{m})$ compared with group B $(1925.4 \pm$ $626.1 \mu \mathrm{m})$ (Mann-Whitney U test, $\mathrm{p}<0.01$ ).

\section{DISCUSSION}

Routine prophylactic, scleral depressed shaving of the vitreous base has been advocated by many as part of PPV for primary RRD. ${ }^{4}$ In this study, we quantified the peripheral vitreous using iOCT by measuring the

Table 2 Comparison of the quantified peripheral vitreous cortex using intraoperative optical coherence tomography during vitreous shaving in group $A$

\begin{tabular}{llll}
\hline & Before finishing shaving & After finishing shaving & P value \\
\hline $\begin{array}{l}\text { Length of the peripheral PVD in the vitreo-retinal angle, } \\
\text { mean } \pm \text { SD }\end{array}$ & $2124.8 \pm 292.8(\mu \mathrm{m})$ & $961.7 \pm 214.7(\mu \mathrm{m})$ & $<0.01$ \\
\hline
\end{tabular}

Group A: vitreous shaving was carried out under a slit lamp microscope illumination with ocular indentation.

PVD, posterior vitreous cortex detachment.; 
Table 3 Comparison of the quantified residual peripheral vitreous cortex using intraoperative optical coherence tomography after finishing vitreous shaving between group $A$ and group $B$

\begin{tabular}{llll}
\hline Length of the peripheral PVD in the vitreo-retinal angle, mean \pm SD & Group A & Group B & P value \\
\hline
\end{tabular}

Group A: vitreous shaving was carried out under a slit lamp microscope illumination with ocular indentation.

Group B: vitreous shaving was performed under a wide-angle noncontact viewing system using chandelier endoillumination with ocular indentation.

PVD, posterior vitreous cortex detachment.;

length of the peripheral PVD in the vitreoretinal angle. To the best of our knowledge, this is the first report to quantify the peripheral vitreous, which was the most prominent result of our study. Shaving under a slit lamp microscope illumination enabled the reduction of the more peripheral vitreous (table 3). Slit lamp observation allowed focusing on the peripheral vitreous more clearly than did the wide-angle viewing system. Furthermore, shaving under a slit lamp microscope illumination required a greater degree of indentation than did the wide-angle viewing system. The combination with the slit lamp allowed the clear visualisation of the peripheral vitreous. ${ }^{8}$ These aspects may explain the greater extension of shaving of the peripheral vitreous observed in group A. In turn, greater shaving of the peripheral vitreous might prevent the formation of a scaffold by the vitreous base and, thus, the development of future anterior proliferative vitreopathy (PVR) and contraction, thus causing new retinal tears and subsequent RD.

The wide-viewing system requires a lower degree of indentation for the observation of the peripheral part of the retina. It is advantageous for micro-incision vitrectomy surgery (MIVS) because the conjunctiva is preserved in this procedure, which hampers strong indentation. In this study, a greater extent of the vitreous was shaved under the wide-viewing system (table 3). A recent study of vitreous shaving without scleral indentation in RRD suggested that a sufficient effect can be obtained if appropriate vitreous shaving is performed. ${ }^{6}$ The findings of vitreoretinal angle via iOCT may be a landmark of the vitreous basal part in the peripheral area or a sign of shaving of the peripheral PVD. ${ }^{7}$ It has been pointed out that the general impression that peripheral vitreous shaving with indentation is associated with superior outcomes may be more a function of the visualisation of the periphery of the retina than of the actual shaving of the vitreous base. ${ }^{6}$ This would be particularly relevant to the early days of $20 \mathrm{G}$ vitrectomy surgery, prior to the era of wide-angle intraoperative visualisation. ${ }^{6}$ Careful surgical manipulation may result in sufficient vitreous shaving with trimming of the vitreous base, regardless of the shaving procedure. Additional more comprehensive studies comparing the different methods of shaving and clinical outcomes are necessary to address this clinical question.
This study had several limitations. First, iOCT quantification of the peripheral vitreous mainly targeted the residual detached PVD, near the vitreous base. The shaving of the anterior vitreous base was not well imaged on the iOCT. And the difficulty of the shaving procedure varies on an individual basis. Second, the outcome of the shaving procedure can depend strongly on the skill of the surgeon as well as on the approach used. The results of this study stem from a single surgeon, with no bias caused by the skill of the surgeon; however, the results may be different if this type of surgery is performed by different surgeons. Future studies comparing the different approaches of vitreous shaving and clinical outcomes should be performed to address the details of this procedure.

In summary, we quantified the residual peripheral vitreous after vitreous shaving using iOCT. We found that slit lamp illumination resulted in enhanced vitreous shaving as compared with wide-angle noncontact viewing system, possibly due to improved peripheral viewing. Quantification of vitreous shaving may have implications in assessing the impact of this step on the success of retinal detachment surgery.

Contributors Conceptualisation: K Nishitsuka. Data curation: K Nishitsuka, K Nishi, HN, YK. Formal analysis: K Nishitsuka, K Nishi. Supervision: HY. Writing \pm original draft: K Nishitsuka. Writing \pm review and editing: K Nishituska. K Nishi, HN, YK, HY.

Funding This work was supported by JSPS KAKENHI (grant JP25462704).

Competing interests None declared.

Patient and public involvement Patients and/or the public were not involved in the design, or conduct, or reporting, or dissemination plans of this research.

Patient consent for publication Not required.

Provenance and peer review Not commissioned; externally peer reviewed.

Data availability statement Data are available upon request.

Open access This is an open access article distributed in accordance with the Creative Commons Attribution Non Commercial (CC BY-NC 4.0) license, which permits others to distribute, remix, adapt, build upon this work non-commercially, and license their derivative works on different terms, provided the original work is properly cited, appropriate credit is given, any changes made indicated, and the use is non-commercial. See: http://creativecommons.org/licenses/by-nc/4.0/.

ORCID iD

Koichi Nishitsuka http://orcid.org/0000-0003-2394-9561

\section{REFERENCES}

1 Lai MM, Ruby AJ, Sarrafizadeh R, et al. Repair of primary rhegmatogenous retinal detachment using 25-gauge transconjunctiva sutureless vitrectomy. Retina 2008;28:729-34.

2 Martínez-Castillo V, Boixadera A, García-Arumí J. Pars plana vitrectomy alone with diffuse illumination and vitreous dissection 
to manage primary retinal detachment with unseen breaks. Arch Ophthalmol 2009;127:1297-304.

3 Weiner AJ, Rao P, Williams G. Large traumatic retinal dialysis associated with prominent vitreous base avulsion. Ophthalmic Surg Lasers Imaging Retina 2018;49:731.

4 Chaturvedi V, Basham RP, Rezaei KA. Scleral depressed vitreous shaving, 360 laser, and perfluoropropane (C3 F8) for retinal detachment. Indian J Ophthalmol 2014;62:804-8.

5 Kuhn F, Aylward B. Rhegmatogenous retinal detachment: a reappraisal of its pathophysiology and treatment. Ophthalmic Res 2014;51:15-31.
6 Tabandeh H, London NJS, Boyer DS, et al. Outcomes of small-gauge vitreoretinal surgery without scleral-depressed shaving of the vitreous base in the era of wide-angle viewing systems. $\mathrm{Br} J$ Ophthalmol 2019;103:1765-8.

7 Nishitsuka K, Nishi K, Namba H, et al. Intraoperative optical coherence tomography imaging of the peripheral vitreous and retina. Retina 2018;38:e20-2.

8 Ohji M, Tano Y. Vitreoretinal surgery with slit-lamp illumination combined with a wide-angle-viewing contact lens. Am J Ophthalmol 2004;137:955-6. 